\title{
Epidemiological investigation of MERS-CoV spread in a single hospital in South Korea, May to June 2015
}

H Y Park ${ }^{1}$, E J Lee², Y W Ryu², Y Kim¹, H Kim¹, H Lee', S J Yi (yiseonju@snu.ac.kr) ${ }^{1}$

1. Gyeonggi Infectious Disease Control Center, Seongnam, Gyeonggi, Republic of Korea

2. Gyeonggi Infectious Disease Control Center Epidemic Intelligence Service, Seongnam, Gyeonggi, Republic of Korea

Park HY, Lee EJ, Ryu YW, Kim Y, Kim H, Lee H, Yi SJ. Epidemiological investigation of MERS-CoV spread in a single hospital in South Korea, May to June 2015. Euro Surveill. 2015;20(25):pii=21169. Available online: http://www.eurosurveillance.org/ViewArticle.aspx?Articleld=21169

In this report, we describe 37 MERS-CoV infection cases (1 primary, 25 secondary, 11 tertiary cases) in a single hospital in South Korea. The median incubation period was six days ( $95 \% \mathrm{Cl}: 4-7$ days) and the duration between suspected symptom onset and laboratory confirmation was 6.5 days (95\% Cl: 4-9). While incubation period was two days longer, the duration from suspected symptom onset to confirmation was shorter in tertiary compared with secondary infections.

\section{Background}

The first case of Middle East respiratory syndrome coronavirus (MERS-CoV) infection in South Korea was reported on 20 May 2015 [1]. As at 24 June the outbreak is ongoing, with 179 incident cases across a dozen affected hospitals [2,3]. After developing symptoms on 11 May, the primary case visited several hospitals, and during his admission to Hospital B in Pyeongtaek between 15 and 17 May [1], 11 other patients, 11 relatives and visitors, and two healthcare workers were directly infected [1-11]. Hospital B was closed on 29 May, and since then, the number of new cases has gradually declined. As at 24 June, 18 days have passed since the last case was laboratory-confirmed in this hospital. As MERS-CoV transmission has not yet ceased fully, data from a single institution able to end the local epidemic may provide some useful information on incubation period and infectious period of the ongoing MERS-CoV outbreak in South Korea.

Data on incident cases at Hospital B, Pyeongtaek, Gyeonggi Province were collected from case investigation reports written by District Community Health Centers responsible for follow-up of respective patients according to their registered location of residence. The reports, submitted to Gyeonggi Provincial Government, were each reviewed by Gyeonggi Infectious Disease Control Center officers. Information on age, sex, underlying comorbidities, MERS-CoV exposure history (i.e. time, place, secondary or tertiary), date of suspected symptom onset (i.e. fever of more than $37.5^{\circ} \mathrm{C}$ or acute respiratory symptoms) [12], etc. was used to investigate incubation period of the MERS-CoV infection and to plot Kaplan-Meier curves for symptom onset and time from symptom onset to laboratory confirmation by order of infection [13]. Package 'survival' in R 3.2.0 (The Comprehensive R Archive Network, http://cran. rproject.org) was used for statistical analysis.

\section{Results of case review}

The primary case visited five hospitals ( 1 in Chungnam province, 2 in Gyeonggi province, and 2 in Seoul), including Hospital B. A total of 36 patients, later identified as suspected MERS cases, were transferred from Hospital B to nine hospitals (4 in Gyeonggi province, 2 in Seoul, 2 in Daejeon, and 1 in Jeonbuk province).

The description of each incident case is shown in the Table. There were 37 cases in total, the mean age was 51.7 years (range 24-79), and 21 cases were male. Twenty cases were patients admitted to Hospital B, 12 were relatives of patients, three were hospital staff who managed the patients, and one was an unrelated visitor. Five of the six fatal cases were patients with high-risk underlying comorbidities, and death occurred within 2-23 days after suspected symptom onset; the case fatality rate was calculated as $16.2 \%$. Twenty-five patients were infected by the MERS-CoV during the admission of the primary case between 15 to 17 May, and 11 others were classified as tentative tertiary infection, i.e. their exposure to MERS-CoV was not related to the spatiotemporal patterns of the primary case (Figure 1).

The incubation period (i.e. number of days between last exposure to a MERS case, to date of suspected symptom onset) for the outbreak in Hospital B ranged between 2 to 15 days, with a median of 6 days (95\% confidence interval ( $\mathrm{Cl}): 4-7$ days) after the last exposure. When separated by infection order, medians for the incubation period were $4(95 \% \mathrm{Cl}: 4-6)$ and 6 days (95\% Cl: 6-8) for secondary and tertiary infection, respectively (Figure 2). The number of days between suspected symptom onset and laboratory confirmation 
TABLE

Description of incident MERS cases in Hospital B, Pyeongtaek, South Korea, May-June 2015 (n=37)

\begin{tabular}{|c|c|c|c|c|c|c|}
\hline No & $\begin{array}{l}\text { Sex/ } \\
\text { age }\end{array}$ & $\begin{array}{l}\text { Relationship to } \\
\text { the primary case }\end{array}$ & $\begin{array}{c}\text { Dates of } \\
\text { hospitalisation } \\
(2015)\end{array}$ & $\begin{array}{c}\text { Date of } \\
\text { suspected } \\
\text { symptom onset } \\
(2015)\end{array}$ & $\begin{array}{c}\text { Date of } \\
\text { laboratory } \\
\text { confirmation } \\
(2015)\end{array}$ & Underlying comorbidity \\
\hline 1 & $M / 68$ & $\mathrm{PC}$ & 15-17 May & 11 May & 20 May & NR \\
\hline 2 & $F / 63$ & $R$ & 15-17 May & 19 May & 20 May & NR \\
\hline $3^{\mathrm{a}}$ & $M / 76$ & $P$ & 16 May & 20 May & 21 May & $\begin{array}{c}\text { Asthma, COPD, MI, } \\
\text { diabetes mellitus, hypertension }\end{array}$ \\
\hline 4 & $F / 46$ & $R$ & 16 May & 23 May & 26 May & NR \\
\hline $5^{\mathrm{a}}$ & $M / 71$ & $\mathrm{P}$ & $\begin{array}{l}\text { 15-21 May, } \\
24-25 \text { May }\end{array}$ & 24 May & 27 May & Post-nephrectomy, unilateral \\
\hline 6 & $F / 28$ & $\mathrm{H}$ & 21 May & 26 May & 27 May & NR \\
\hline 7 & $M / 56$ & $\mathrm{P}$ & 9-27 May & 19 May & 29 May & Pneumonia \\
\hline 8 & $M / 44$ & $R$ & 16 May & 19 May & 29 May & NR \\
\hline 9 & $\mathrm{~F} / 79$ & $\mathrm{P}$ & 15-29 May & 20 May & 29 May & $\mathrm{NR}$ \\
\hline 10 & $\mathrm{~F} / 49$ & $\mathrm{P}$ & 15-29 May & 21 May & 29 May & NR \\
\hline 11 & $M / 49$ & $R$ & 15-17 May & 21 May & 29 May & NR \\
\hline 12 & $M / 35$ & $P$ & 13-19 May & 21 May & 30 May & Pneumonia \\
\hline 13 & $M / 35$ & $R$ & 15-21 May & 22 May & 3о May & $\mathrm{NR}$ \\
\hline 14 & $M / 40$ & $P$ & 15-17 May & 20 May & 31 May & NR \\
\hline 15 & $M / 45$ & $R$ & 12-16 May & 22 May & 31 May & NR \\
\hline 16 & $\mathrm{~F} / 77$ & $\mathrm{P}$ & 15-16 May & 20 May & 31 May & NR \\
\hline 17 & $M / 60$ & $R$ & 16-18 May & 28 May & 01 Jun & NR \\
\hline 18 & $M / 40$ & $P$ & 12-21 May & 23 May & 01 Jun & NR \\
\hline 19 & $\mathrm{~F} / 59$ & $R$ & 12-18 May & 23 May & o1 Jun & NR \\
\hline 20 & $F / 39$ & $R$ & 13-20 May & 27 May & 01 Jun & NR \\
\hline $21^{\mathrm{a}}$ & $\mathrm{F} / 57$ & $\mathrm{P}$ & 11-18 May & 23 May & 01 Jun & $\begin{array}{c}\text { Asthma, hypertension, } \\
\text { iatrogenic Cushing syndrome }\end{array}$ \\
\hline 22 & $M / 43$ & $R$ & 13-20 May & 21 May & 01 Jun & NR \\
\hline 23 & $M / 55$ & $\mathrm{P}$ & 4-29 May & 01 Jun & 01 Jun & Undefined cardiac disease \\
\hline $24^{\mathrm{a}}$ & $M / 58$ & $R$ & 26 May & 29 May & 02 Jun & Diabetes mellitus \\
\hline 25 & $\mathrm{~F} / 77$ & $\mathrm{P}$ & 15-17 May & 19 May & 02 Jun & NR \\
\hline 26 & $M / 54$ & $R$ & 15 May & 22 May & 03 Jun & NR \\
\hline 27 & $M / 47$ & $\mathrm{~V}$ & 15 May & 20 May & 03 Jun & NR \\
\hline 28 & $F / 25$ & $\mathrm{H}$ & 15-17 May & 20 May & O4 Jun & NR \\
\hline 29 & $M / 45$ & $\mathrm{P}$ & 14-27 May & o4 Jun & 05 Jun & NR \\
\hline 30 & $M / 62$ & $P$ & 20-28 May & 02 Jun & 05 Jun & NR \\
\hline 31 & $M / 24$ & $\mathrm{P}$ & 22-28 May & 31 May & 05 Jun & NR \\
\hline $32^{\mathrm{a}}$ & $\mathrm{F} / 54$ & $\mathrm{P}$ & 19-20 May & 25 May & 29 May & Bronchiectasis, hypertension \\
\hline 33 & $F / 24$ & $\mathrm{H}$ & 28 May & 29 May & 05 Jun & NR \\
\hline 34 & $\mathrm{~F} / 51$ & $\mathrm{P}$ & 18-28 May & 01 Jun & 05 Jun & $\mathrm{NR}$ \\
\hline $35^{\mathrm{a}}$ & $\mathrm{F} / 72$ & $\mathrm{P}$ & 12-21 May & o3 Jun & 05 Jun & NR \\
\hline 36 & $F / 54$ & $\mathrm{P}$ & 23-28 May & 31 May & 06 Jun & NR \\
\hline 37 & $M / 51$ & $\mathrm{P}$ & 26-28 May & 04 Jun & 06 Jun & NR \\
\hline
\end{tabular}

COPD: chronic obstructive pulmonary disease; F: female; H: healthcare worker; M: male; MERS: Middle East respiratory syndrome; MI: myocardial infarction; NR: not reported; P: patient at same hospital; PC: primary case; R: relative; V: visitor at hospital.

a These cases died during follow-up.

Numbering of cases differs from the numbering announced by South Korea Ministry of Health and Welfare.

for all cases ranged from o to 15 , with a median of 6.5 days (95\% Cl: 4-9). Upon separation by infection order, medians were 9 ( $95 \% \mathrm{Cl}: 8-11)$ and 4 days (95\% $\mathrm{Cl}: 3-6)$ for secondary and tertiary infection, respectively (Figure 3).

\section{Discussion and conclusion}

The district hospital under study is the first single institution in South Korea that reported an almost full course of epidemic progress with a transmission chain of MERS-CoV infections from a primary case to tertiary cases over six districts. We discovered a prolonged 
Cases of MERS-CoV infection by date, Hospital B, Pyeongtaek, South Korea, May-June 2015 (n=37)

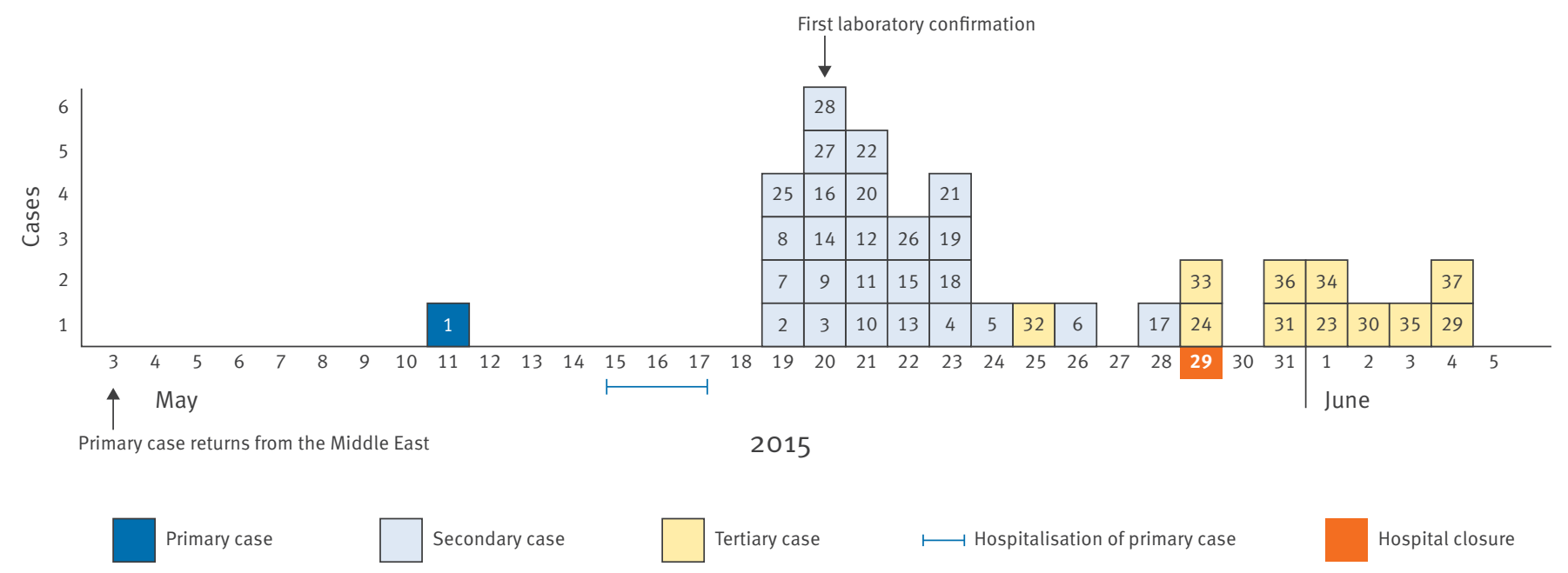

incubation period and shortened symptom-to-laboratory confirmation duration in tertiary infections compared with secondary infections. The prodromal period was defined as the duration between the suspected symptom onset and the peak of fever $\left(338.5^{\circ} \mathrm{C}\right)$. As we consider the prodromal period to be longer in tertiary infections, the length of the incubation period may have been overestimated (more than 14 days).

Initially, information on the travel history of the primary case was missing, and since MERS had not been encountered in South Korea before, this medium-scale local hospital was unaware of the MERS-CoV infection in progress until 3 days after the primary case was discharged. Thus isolation and protection measures were delayed; this, in combination with other environmental factors (e.g. relative/healthcare worker sleeping in the same room with patients, insufficient air-conditioning, moving of patients to other rooms/wards, etc.) and an unexpected high infectivity of patients with rapidly deteriorating pneumonia, resulted in a high number of secondary and tertiary cases [14].

\section{FIGURE 2}

Kaplan-Meier curve for days to suspected symptom onset after the last exposure to a laboratory-confirmed MERS case, Hospital B, Pyeongtaek, South Korea, May-June 2015 ( $\mathrm{n}=37)$

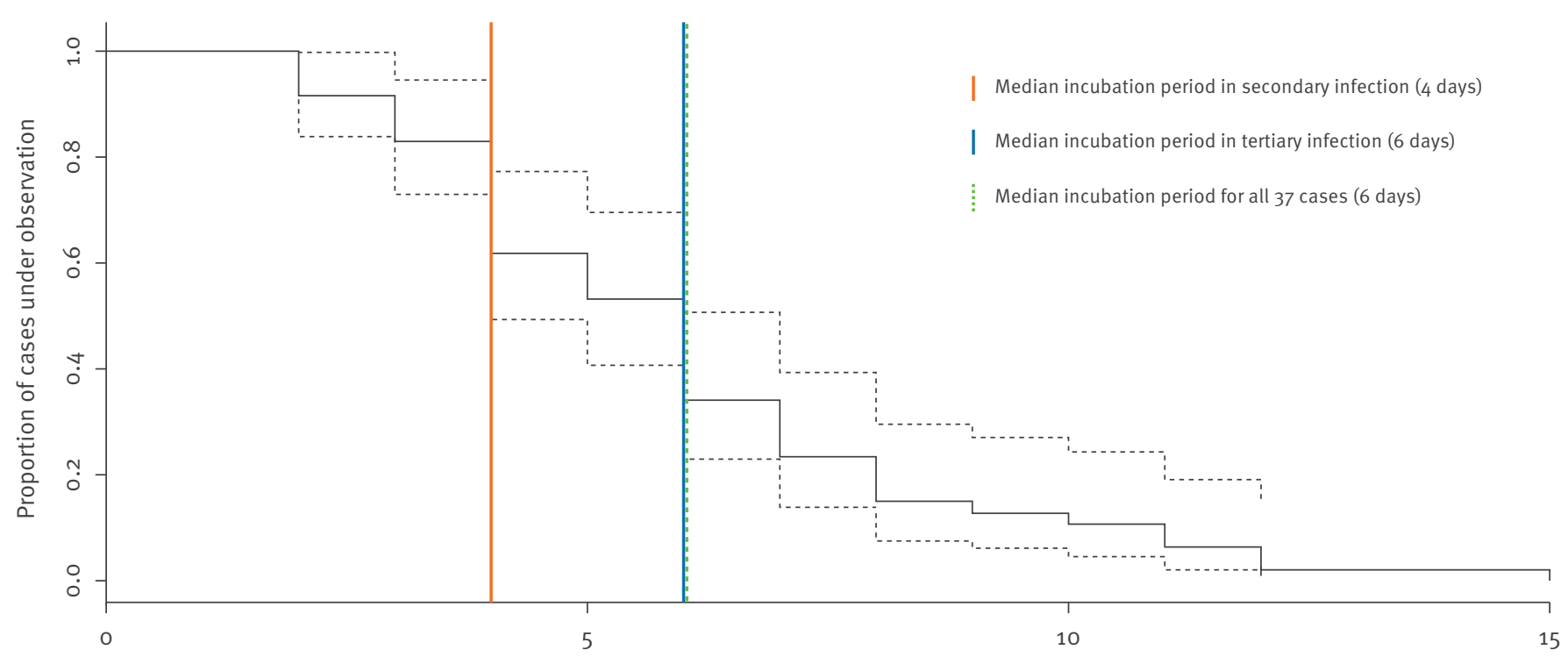

Days between last exposure to a MERS case and suspected symptom onset

MERS: Middle East respiratory syndrome. 
Kaplan-Meier curve for days to laboratory confirmation after suspected MERS-CoV symptom onset, Hospital B, Pyeongtaek, South Korea, May-June $2015(n=37)$

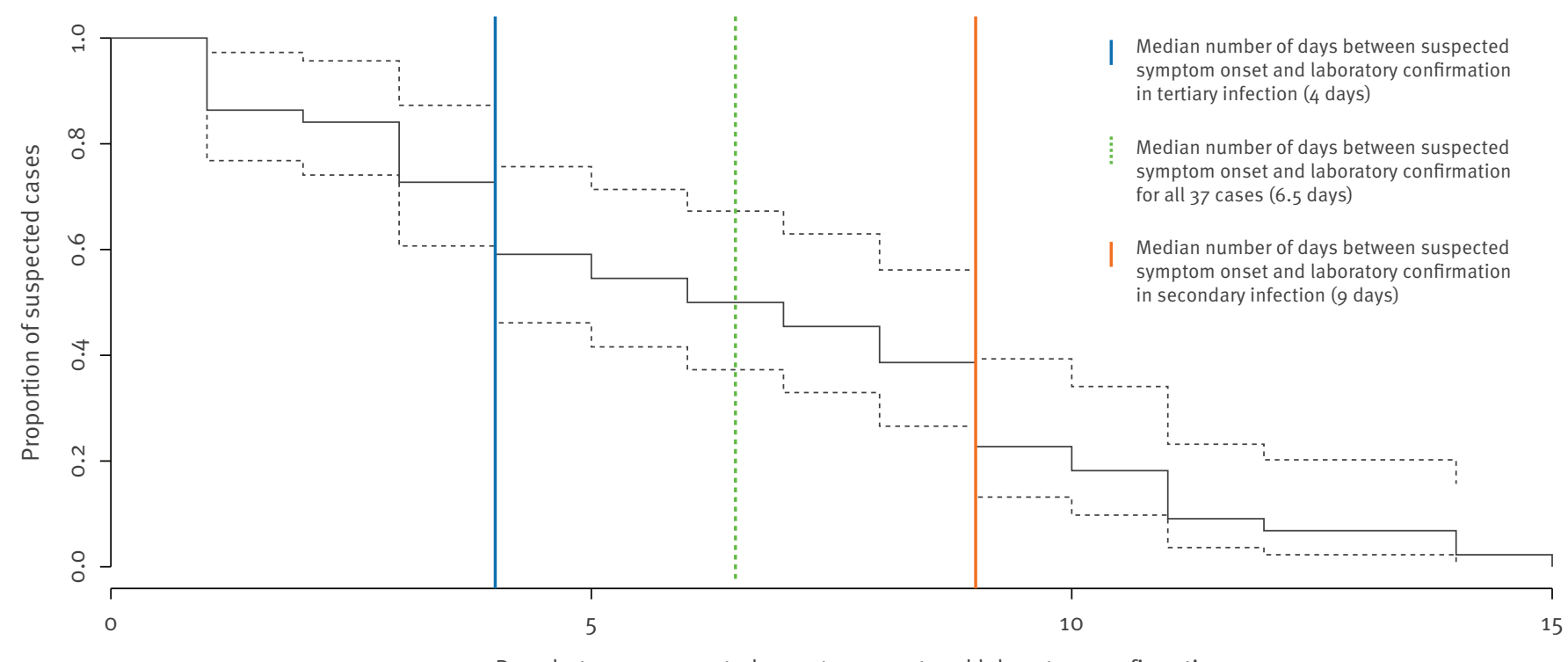

Days between suspected symptom onset and laboratory confirmation

MERS: Middle East respiratory syndrome.

The shortened duration of symptom-to-laboratory confirmation in tertiary cases may reflect the disease recognition and consecutive earlier testing. However, explanations for a longer incubation period in tertiary infections, compared with secondary infections, require further investigations.

Even though based on small numbers, important implications of our results may apply, predominantly to the current medical delivery system in South Korea. In this system, there are frequent patient transfers between outpatient clinics, outpatient and inpatient general hospital departments, as well as highly specialised hospitals. When healthcare providers are not informed that there have been MERS cases in a hospital from where a patient has been transferred, they will be unable to take adequate measures for infection prevention. This may result in additional transmission. Concurrent delay of contact tracing and isolation may lead to substantial exposure to infection in other medical institutions and even in communities. At the same time, as tertiary infections show longer median incubation period compared with secondary infections (i.e. more time is available before infected cases at tertiary level are distinguished by their symptoms), active identification of contacts and their appropriate management would facilitate earlier infection control, and increase the opportunity for preventing tertiary infections.

Thus, we would like to suggest that any effective prevention measure should include an exhaustive review of information on incident cases, especially on their contacts, at an as early as possible stage. With cumulating experience on MERS cases and their contacts and shorter duration of symptom-to-laboratory confirmation, we hope the end of the ongoing epidemic in South Korea can soon be brought to an end. The MERS-CoV outbreak can be declared ended in South Korea when a 28-day-period (two incubation periods) has elapsed after the last laboratory-confirmed case.

\section{${ }^{\star}$ Expression of concern}

A note of concern has been published for this paper on 1 July 2015. It has been brought to our attention that some of the authors may not have been informed about the content of this paper. There is a lack of clarity regarding rights to use the data. The editorial team are investigating what action needs to be taken.

\section{Conflict of interest}

None declared.

Authors' contributions

HYP and S-JY planned, analysed and wrote the paper. EJL and YWR carried out field study and collected epidemiological data. All authors critically reviewed epidemiological data.

\section{References}

1. World Health Organization (WHO). Middle East respiratory syndrome coronavirus (MERS-CoV) - Republic of Korea. Geneva: WHO; 24 May 2015. Available from: http://www.who. int/csr/don/24-may-2015-mers-korea/en/. Last accessed: 9 June 2015 . 
2. Ministry of Health and Welfare (MOHW) and Korean Centers for Disease Control and Prevention(KCDC). Press release summary - MERS Statistics; 24 June 2015. Available from: http://cdc.go.kr/CDC/info/CdcKrHealtho298. jsp?menulds $=$ HOMEo01-MNU1132-MNU1013\&fid $=5767 \& q$ type $=\& q \_$value $=\& c i d=63703 \&$ pageNum $=$. Last accessed: 24 June 2015 .

3. Ministry of Health and Welfare (MOHW) and Korean Centers for Disease Control and Prevention(KCDC) . List of hospitals with known MERS exposure; 22 June 2015. Available from: http://cdc.go.kr/CDC/info/CdcKrHealtho298. jsp?menulds $=$ HOMEO01-MNU1132-MNU1013\&fid $=5767 \& q$ type $=\& q \_$value $=\& \operatorname{cid}=63640 \&$ pageNum $=$. Last accessed: 24 June 2015.

4. World Health Organization (WHO). Middle East respiratory syndrome coronavirus (MERS-CoV) - Republic of Korea. Geneva: WHO; 30 May 2015. Available from: http://www.who. int/csr/don/30-may-2015-mers-korea/en/. Last accessed: 9 June 2015.

5. World Health Organization (WHO). Middle East respiratory syndrome coronavirus (MERS-CoV) - Republic of Korea. Geneva: WHO; 31 May 2015. Available from: http://www.who. int/csr/don/31-may-2015-mers-korea/en/. Last accessed: 9 June 2015.

6. World Health Organization (WHO). Middle East respiratory syndrome coronavirus (MERS-CoV) - Republic of Korea. Geneva: WHO; 1 June 2015. Available from: http://www.who. int/csr/don/01-june-2015-mers-korea/en/. Last accessed: 9 June 2015 .

7. World Health Organization (WHO). Middle East respiratory syndrome coronavirus (MERS-CoV) - Republic of Korea. Geneva: WHO; 4 June 2015. Available from: http://www.who. int/csr/don/o4-june-2015-mers-korea/en/. Last accessed: 9 June 2015.

8. World Health Organization(WHO). Middle East respiratory syndrome coronavirus (MERS-CoV) - Republic of Korea. Geneva: WHO; 5 June 2015. Available from: http://www.who. int/csr/don/05-june-2015-mers-korea/en/. Last accessed: 9 June 2015 .

9. World Health Organization(WHO). Middle East respiratory syndrome coronavirus (MERS-CoV) - Republic of Korea. Geneva: WHO; 6 June 2015. Available from: http://www.who. int/csr/don/o6-june-2015-mers-korea/en/. Last accessed: 9 June 2015 .

10. World Health Organization(WHO). Middle East respiratory syndrome coronavirus (MERS-CoV) - Republic of Korea. Geneva: WHO; 8 June 2015. Available from: http://www.who. int/csr/don/o8-june-2015-mers-korea/en/. Last accessed: 9 June 2015 .

11. World Health Organization(WHO). Middle East respiratory syndrome coronavirus (MERS-CoV) - Republic of Korea. Geneva: WHO; 9 June 2015. Available from: http://www.who. int/csr/don/o9-june-2015-mers-korea/en/. Last accessed: 9 June 2015 .

12. Zumla A, Hui DS, Perlman S. Middle East respiratory syndrome. Lancet. 2015 Jun 3. pii: So140-6736(15)60454-8. doi: 10.1016/ So140-6736(15)60454-8. [Epub ahead of print] Review.

13. Cowling BJ, et al. Comparative epidemiology of human infections with avian influenza $\mathrm{A} \mathrm{H}_{7} \mathrm{~N}_{9}$ and $\mathrm{H}_{5} \mathrm{~N}_{1}$ viruses in China: a population-based study of laboratory-confirmed cases. Lancet. 2013;382(9887):129-37. http://dx.doi. org/10.1016/S0140-6736(13)61171-X PMID:23803488

14. Hui DS, Perlman S, Zumla A. Spread of MERS to South Korea and China. Lancet Respir Med. 2015 Jun 4. pii: S22132600(15)00238-6. doi: 10.1016/S2213-2600(15)00238-6. [Epub ahead of print] 